\title{
Praecordial surface mapping after exercise in evaluation of propranolol for angina pectoris ${ }^{\star}$
}

\author{
KIM FOX, ANDREW SELWYN, DAVID OAKLEY, ANNE JONATHAN, \\ JOHN SHILLINGFORD
}

\begin{abstract}
From the Division of Cardiovascular Disease, Royal Postgraduate Medical School, Hammersmith Hospital, London
\end{abstract}

SUMMARY The effect of propranolol on ST depression in the praecordial 16 lead electrocardiogram was observed in 52 patients before and after treatment, both at rest and after exercise. In a further 20 patients exercise tests repeated on separate days two months apart showed that the technique gave reproducible results. A variable relation between symptomatic relief and praecordial exercise-induced ST segment depression was noted. Use of a single fixed-position chest lead (V5) was shown to be less accurate. The relief of symptoms alone is probably an inadequate guide to the success of medical treatment, which should control not only angina but also the manifestations of ischaemia on the praecordial electrocardiogram.

A non-invasive, objective means of assessing the effects of medical treatment would be invaluable for the management of patients with ischaemic heart disease, providing an important adjunct to symptomatic relief in determining the adequacy of treatment. Though exercise testing and measurements of exercise tolerance have proved useful, the subjective aspects involved in training and in pain assessment limit the usefulness of these techniques. ${ }^{1}$ Few will deny the value of beta-blockade in controlling angina yet studies reporting the effects of propranolol on exercise-induced ST segment depression have been conflicting. ${ }^{2-4}$ This must, in part, be related to the lack of quantitative data when measurements of the depth of ST depression are made at only one or, at best, six praecordial sites. The introduction of praecordial surface mapping after exercise adds an extra dimension to the standard lead systems since both the area and severity of ST segment changes that are projected on to the front of the chest can be measured..$^{5}$ The present study was designed, therefore, to determine the effects of established long-term beta-blockade on the praecordial projection of ST segment changes and to illustrate the value of this noninvasive objective technique in evaluating drug treatment in each individual patient.

* This work was supported by a grant from the British Heart Foundation.

Received for publication 31 May 1979

\section{Methods}

Fifty-two patients (38 men, 14 women) with frequent incapacitating angina pectoris were studied. All reported daily episodes of chest pain and all developed ST segment depression after exercise. The mean age was 57 years. Before starting medical treatment, a 16 point praecordial electrocardiogram was recorded before and after exercise using a directwriting ink jet Mingograf (Elema Schonander) recording on four channels simultaneously. ${ }^{6}$ The 16 electrodes were connected to the electrocardiograph using a four-way switch. All patients developed chest pain during the exercise test, and this was used as the indication to stop the test.

The 16 unipolar electrodes were evenly distributed over the left hemi-thorax and connected to a central Wilson terminal. One of the positions corresponded exactly to V5 and was selected to act as the single chest lead for comparison purposes. Graded maximal exercise tests were performed using a bicycle ergometer. ${ }^{7}$ Recordings were made before and immediately after exercise and then at regular intervals for 10 minutes or until the electrocardiogram had returned to the pre-exercise resting state. The connection of a patient took 10 to 15 minutes, and each 16 lead praecordial map about 10 seconds to record. The workload achieved by each patient was noted.

After the initial test, patients received treatment 
as outpatients and were seen at least every two weeks. Propranolol was started at a dose of $10 \mathrm{mg}$ three times daily and increased according to patient tolerance, symptomatic relief, and serial heart rate and blood pressure recordings. The mean final dose used was $300 \mathrm{mg}$ daily in divided doses (range 120 to $480 \mathrm{mg}$ ) and compliance with therapy was assessed by questioning and by noting an adequate bradycardia at rest. When the optimal dose of propranolol in terms of symptomatic relief, heart rate response (less than 65/min), and drug tolerance had been achieved for each patient for at least two weeks, the praecordial electrocardiogram was repeated before and after exercise using the same procedure and workload as at the first test. Patients not suitable for treatment with propranolol, or unable to tolerate the drug, or considered not to be taking it properly were excluded from the study before the second test and are not part of these data.

A further 20 patients receiving no drug treatment were studied to determine the reproducibility of the praecordial area and severity of the ST segment depression. Exercise tests using the above procedure were repeated on separate days two months apart and the praecordial electrocardiogram was recorded before and after exercise. The same workload was used in both tests.

The criteria of the Scandinavian Committee on ECG Classification ${ }^{8}$ were used to interpret the electrocardiograms. ST segment changes were read with reference to the $P Q$ segment and depression was considered to be present if there was $1 \mathrm{~mm}$ or more of shift lasting for 0.08 second or longer. Contour maps of the area of ST segment change were drawn ${ }^{9}$; the total area being defined as the number of praecordial positions showing a significant ST segment alteration, and severity of $\Sigma S T$ as the total ST segment shift in millimetres for all the 16 positions.

\section{Results}

The mean resting and peak exercise heart rates $( \pm 1$ standard deviation) were, respectively, $74 \pm 8$ and $138 \pm 14$ beats a minute before starting propranolol, and $56 \pm 5$ and $92 \pm 6$ beats a minute with treatment. The mean blood pressure before and after propranolol was $137 / 7$ i and $117 / 68 \mathrm{mmHg}$, respectively. All patients were able to achieve the same workload after treatment as at the beginning of the study
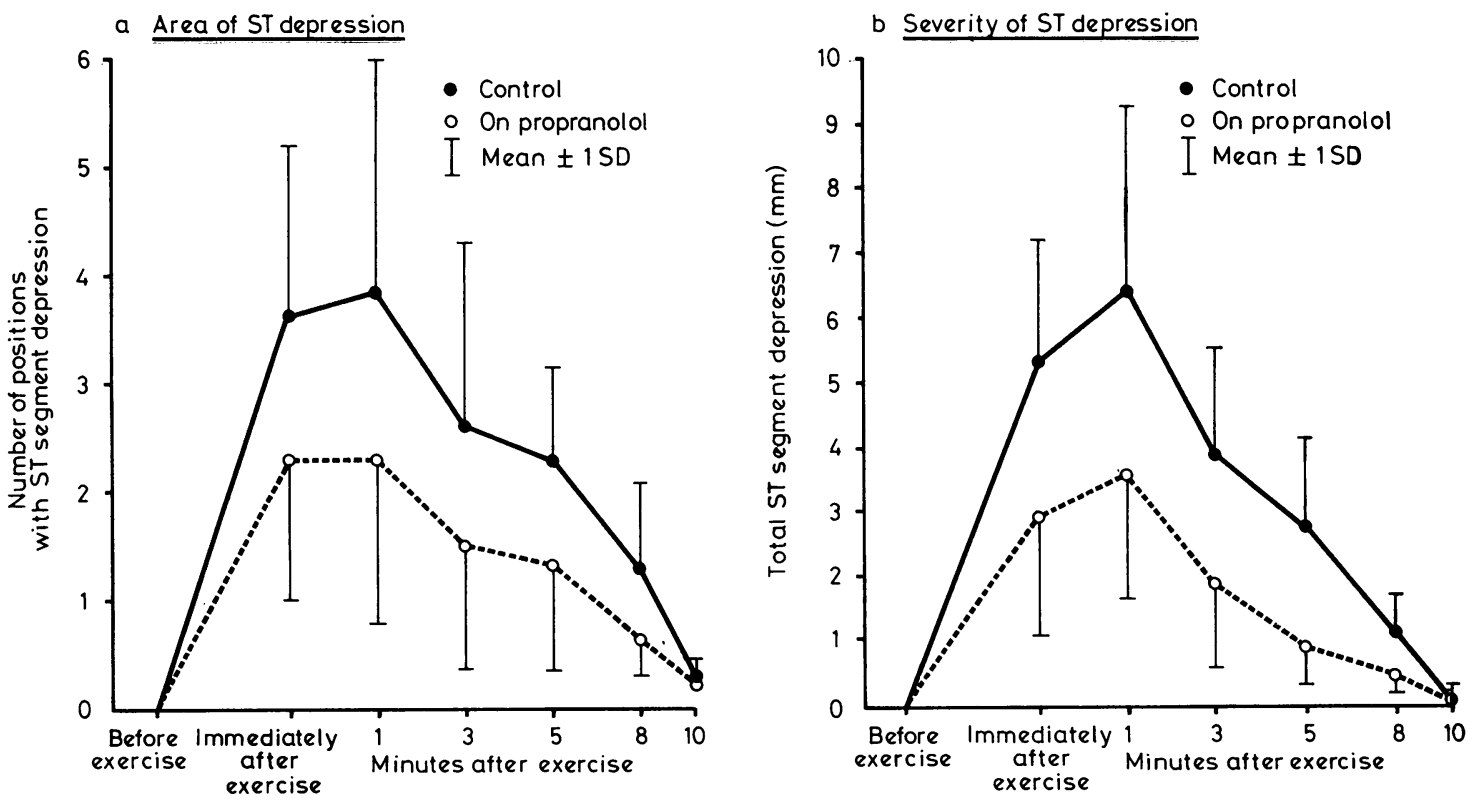

Fig. 1 (a) The mean number of praecordial positions showing ST segment depression before and after exercise is shown before (control) and on treatment with propranolol in 52 patients. There were significantly fewer praecordial positions with exercise-induced ST segment depression during treatment with propranolol. (b) The total ST segment depression in millimetres for all 16 leads before and after exercise is shown before (control) and on treatment with propranolol in 52 patients. There was significantly less exercise-induced ST segment depression during treatment with propranolol. Mean and one standard deviation (SD) calculated; for clarity either the upper or lower extremity of the standard deviation is displayed. 
(mean $22140 \pm 9300$ Watt s).

The mean time between the first and second exercise tests was eight \pm three weeks.

Fig. $1 \mathrm{a}$ and $1 \mathrm{~b}$ show the mean praecordial area and severity of ST segment depression recorded before and after exercise in the 52 patients before and after treatment with propranolol. Both the maximum area and maximum severity of exerciseinduced ST segment depression were diminished after treatment with propranolol $(p<0 \cdot 01)$. The wide individual variation is shown by the large standard deviation and the results have accordingly been divided into three groups.

\section{GROUP 1: COMPLETE RESOLUTION OF} EXERCISE-INDUCED PRAECORDIAL ST SEGMENT CHANGES WITH PROPRANOLOL (16 PATIENTS) All these patients were free from pain on exercise when on propranolol. Nine had become free from symptoms at any time and seven now had chest pain infrequently. The single chest lead (V5) inevitably also showed complete resolution of ST segment changes after treatment (mean ST segment depression beforehand $1.25 \mathrm{~mm}$ ). Fig. 2 recorded from a 48-year-old man shows an example. Both contour maps were obtained one minute after exercise, before and after propranolol $240 \mathrm{mg}$ daily. This patient had been free from symptoms for four weeks before the second test was performed. Though exercising to the same workload, he did not develop ST segment depression.

\section{GROUP 2: IMPROVEMENT IN EXERCISE-}

INDUCED PRAECORDIAL ST SEGMENT CHANGES WITH PROPRANOLOL BUT NOT COMPLETE RESOLUTION (16 PATIENTS)

Ten of these 16 patients were free from pain on exercise when on propranolol. Five had become free from symptoms at any time, seven now had chest pain only occasionally, but four still had frequent episodes of angina. The single chest lead (V5) showed complete resolution of ST segment changes in eight patients (mean ST segment depression before and after treatment 1.7 and $1 \mathrm{~mm}$, respectively). Fig. 3 shows the sequence of contour maps recorded from one of these eight patients. Note that at position V5 there were no ST segment changes after treatment with propranolol. This patient was one of those now free from symptoms and without angina on exercise.
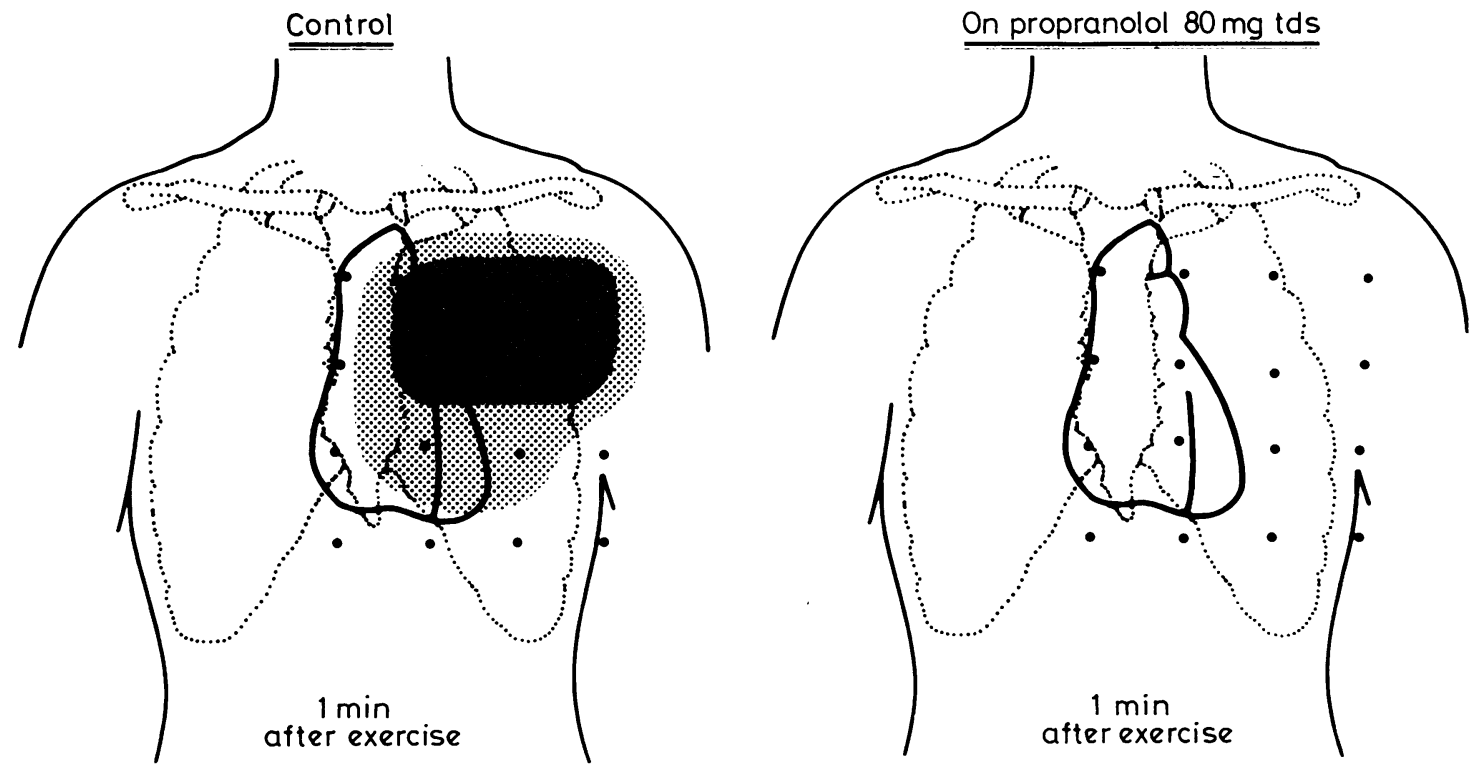

ST segment depression
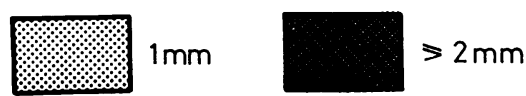

Fig. 2 The maximum praecordial area of $S T$ segment depression recorded after exercise (1 minute) is shown before treatment with propranolol (control). After propranolol no ST segment depression was recorded after exercise when the patient was exercised to the same work load. 
GROUP 3: NO CHANGE IN EXERCISEINDUCED PRAECORDIAL ST SEGMENT CHANGES WITH PROPRANOLOL (20 PATIENTS)

Of these 20 patients, 12 were free from pain on exercise when on propranolol; one was now free from symptoms at any time, six had only occasional chest pain, and 13 still had frequent episodes of angina. The single chest lead showed complete resolution of ST segment changes in four patients (mean ST segment depression before and after treatment 1.7 and $1.2 \mathrm{~mm}$, respectively). Fig. 4 shows the sequence of contour maps from a typical patient in this group. On propranolol this patient now had infrequent angina and was free of pain when exercised.

\section{REPRODUCIBILITY}

The mean praecordial area and severity of ST segment depression found at the first and second exercise tests in the 20 patients in whom reproducibility studies were performed are shown in Fig. 5a and $5 \mathrm{~b}$. There was no significant difference between the two tests before or at any time after exercise (p $>0.05)$.

\section{Discussion}

This study shows the value of being able to measure both the praecordial area and the severity of ST segment depression projected on to the front of the chest. Propranolol certainly reduces the frequency of angina and improves exercise tolerance but this does not necessarily indicate an improvement in the imbalance between myocardial oxygen supply and demand. Theoretically, the drug can increase coronary vascular resistance and this might make matters worse, though, in practice, such an effect is likely to be outweighed by the reduction in myocardial oxygen requirements. ${ }^{10}$ Nevertheless, it is unclear whether relief of angina indicates total correction of the myocardial oxygen deficit or mere improvement in it. ${ }^{11}$ Exercise, of course, exaggerates ischaemia, which, being frequently accompanied by ST depression, enables this point to be studied in so far as this electrocardiographic sign is specific. Though there is a variety of causes for this electrocardiographic sign, for example digitalis, hypertension, aortic stenosis, provided these are excluded, exercise-induced, downsloping or planar ST seg-
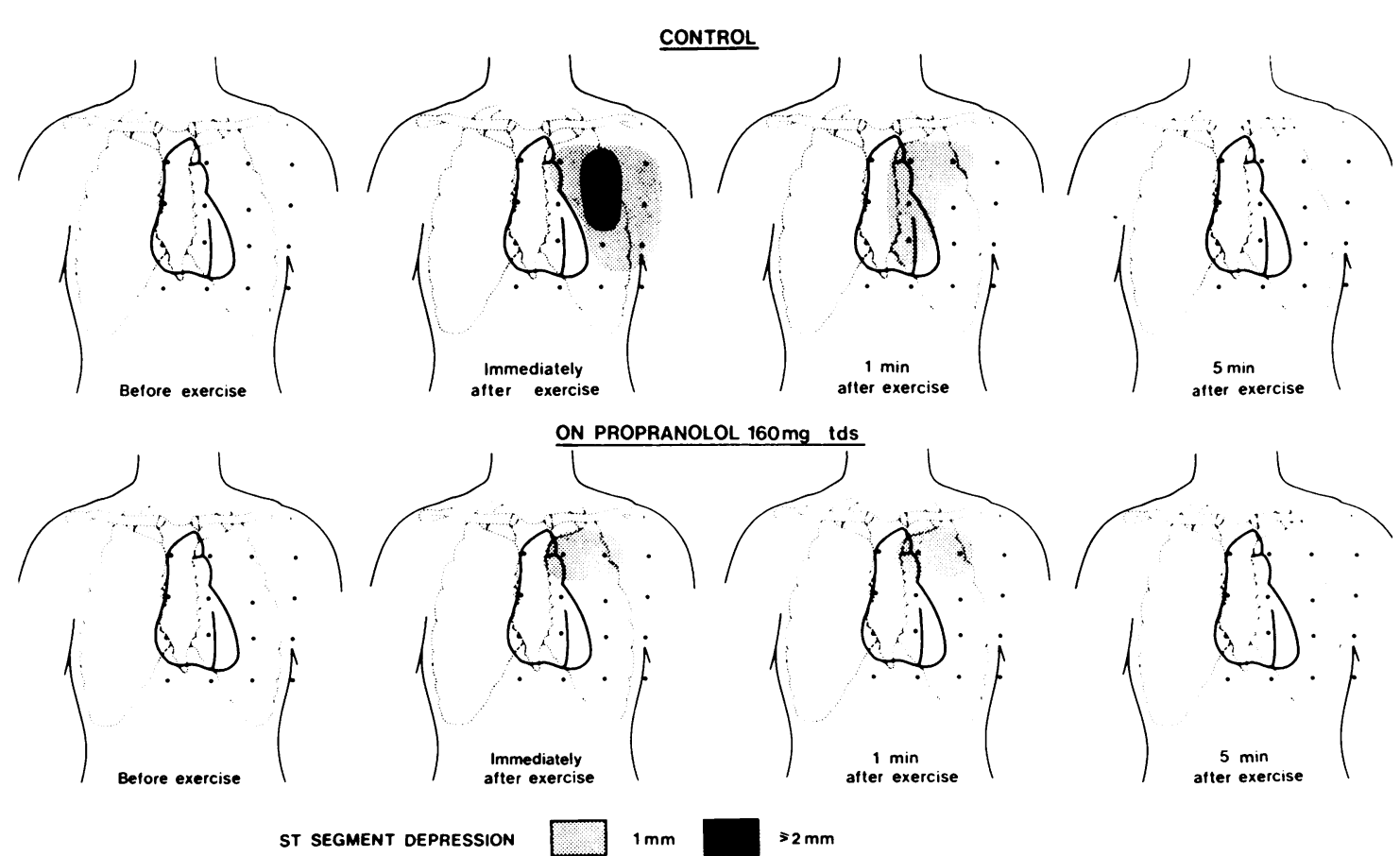

Fig. 3 The sequence of contour maps obtained before (control) and on treatment with propranolol are shown. While on treatment with propranolol the praecordial area of ST segment depression was smaller and would not have been detected if only a single chest lead (V5) had been used. 
ment depression has been found to be specific for coronary artery disease. ${ }^{5}$ Furthermore, experimental evidence has shown that it probably represents patchy myocardial ischaemia. ${ }^{12}$ However, there are spatial and electrophysiological variables which prevent there being a simple quantitative relation between the extent of ischaemia and the area of abnormality on the electrocardiographic surface map, ${ }^{13}$ and changes only have meaning if each patient acts as his own control.

This study has shown that the relief of angina is not necessarily accompanied by abolition of the electrocardiographic manifestations of ischaemia. ST segment changes after exercise increase as ischaemia increases; and the surface mapping technique can be used to make serial measurements in any individual patient, thus affording an objective measure of progress.

Furthermore, since angina pectoris and thereby ST segment depression can occur in a variety of circumstances, yet not necessarily always consistently, any technique to be used for serial measurements of ST segment changes must be reproducible and this has been shown for surface mapping, provided patients are exercised to the same workload under identical conditions on each occasion.

The discrepancies between previous reports on the effects of beta-blockers in angina become clear when the use of the single chest lead (V5) is compared with praecordial surface mapping in our patients. In 12 of them when on propranolol, reliance on V5 alone would have failed to identify exercise-induced ST segment depression that was present in other areas of the praecordium. Given the inconstant relation between the heart and the front of the chest with alterations in position, respiration, and heart rate, this is not surprising, and no single fixed position lead can be considered a reliable indicator of ST segment change.

The relations between symptomatic relief, exercise-induced chest pain, and the praecordial electrocardiographic signs of ischaemia after propranolol are of particular interest. The relief of symptoms did not necessarily run parallel with the effective control of exercise-induced ST changes, though an improvement in symptoms was never found in association with a deterioration in the
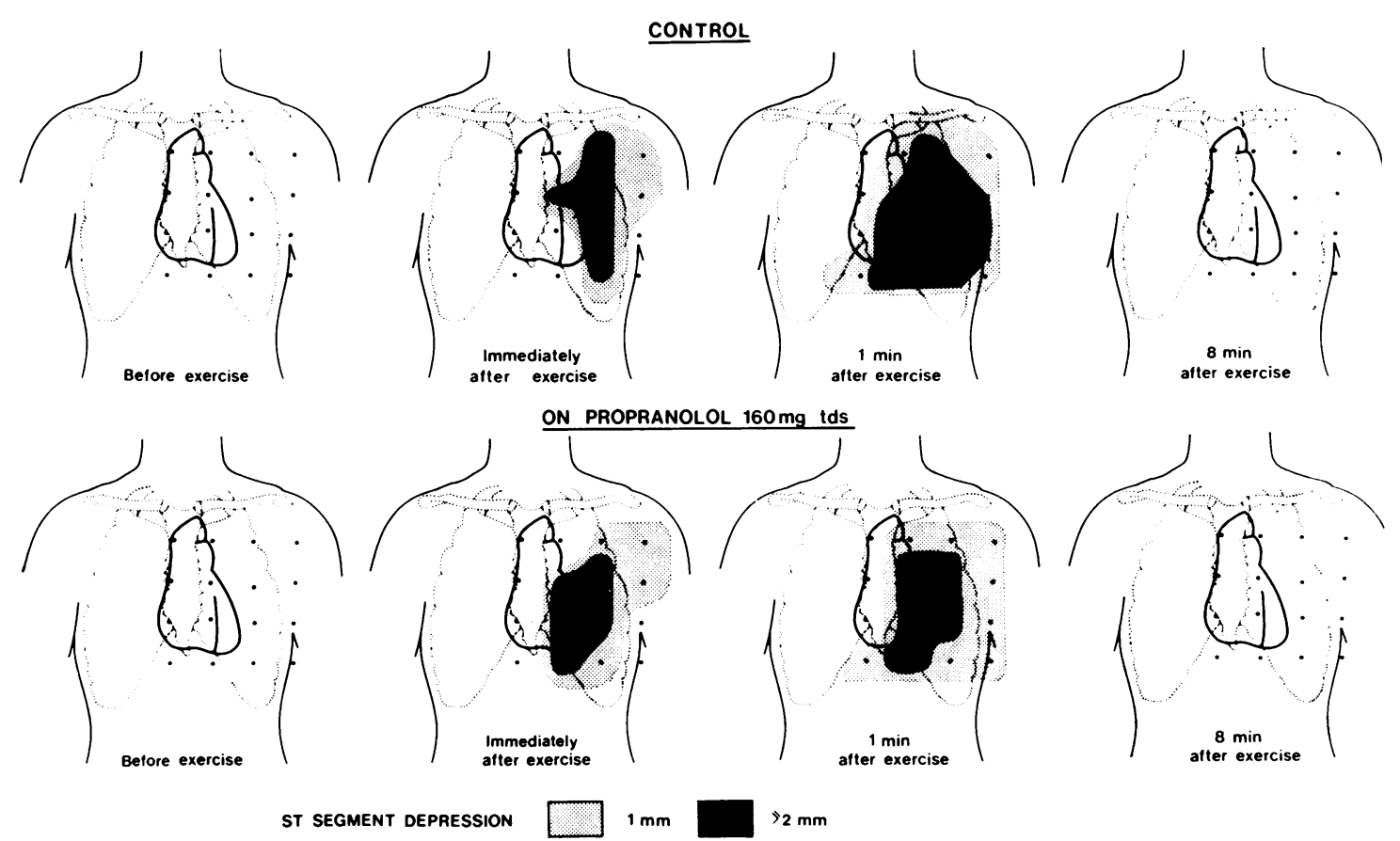

Fig. 4 The sequence of contour maps obtained before (control) and on treatment with propranolol are shown in a patient in whom the praecordial area of ST segment change was little affected by the propranolol. 
electrocardiogram. A reduction in exercise-induced chest pain was a more reliable accompaniment to the relief of symptoms but correlated poorly with any improvement in ST segment depression. The significance of exercise-induced ST segment changes in the absence of pain in patients on propranolol is unclear and further work is necessary to show if
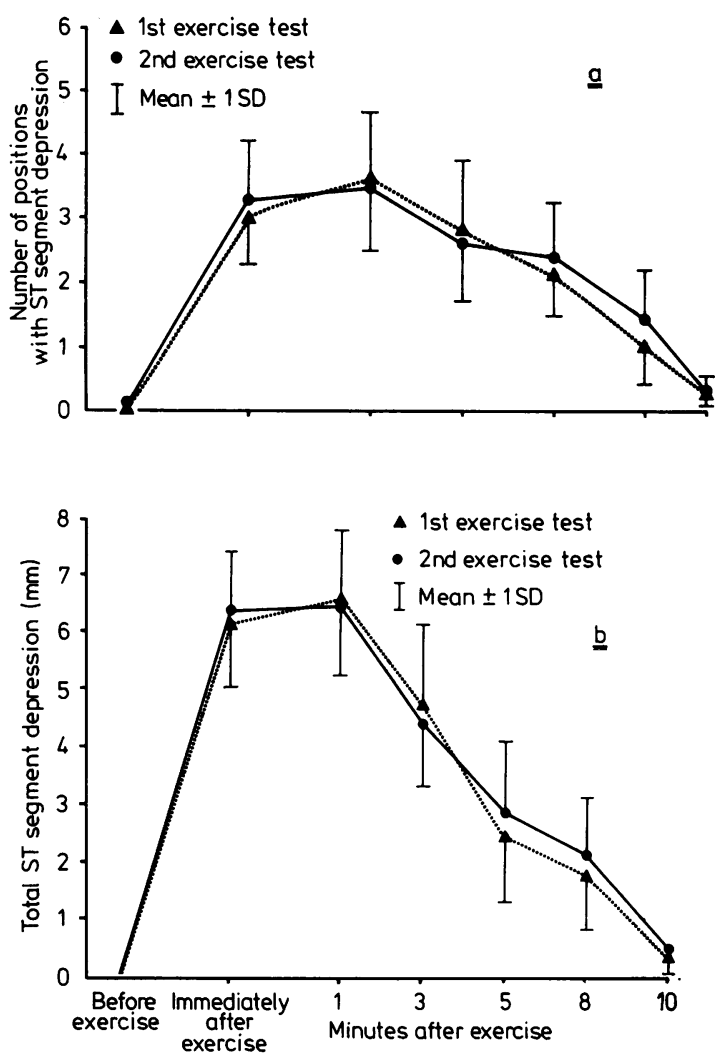

Fig. 5 The mean number of praecordial positions showing $S T$ segment depression (a) and the mean $S T$ segment depression in millimetres for all 16 leads (b) is shown for each of the two exercise tests in the 20 patients in whom reproducibility studies were performed. Both the praecordial area and severity were similar before and at each time after exercise in both tests. Mean and standard deviations displayed as in Fig. 1. there is any prognostic improvement when the electrocardiographic manifestations of myocardial ischaemia are controlled.

\section{References}

${ }^{1}$ Frishman W, Smithen C, Befler B, Kligfield P, Killip T. Non-invasive assessment of clinical response to oral propranolol. Am f Cardiol 1975; 35: 635-44.

${ }^{2}$ Gillam PMS, Prichard BNC. Propranolol in the therapy of angina pectoris. Am $\mathcal{F}$ Cardiol 1965; 18: 366-9.

${ }^{3}$ Hamer J, Grandjean T, Melendez L, Sowton GE. Effects of propranolol (inderal) on exercise tolerance in angina pectoris. $B r$ Heart $\mathcal{F} 1966$; $28: 414-8$.

${ }^{4}$ Gianelly RE, Triester BL, Harrison DC. The effects of propranolol on exercise-induced ischemic ST segment depression. Am f Cardiol 1969; 24: 161-5.

${ }^{5}$ Fox KM, Selwyn AP, Shillingford JP. Praecordial surface mapping after exercise: improved diagnosis of coronary artery disease. $\mathrm{Br} \mathrm{Med} \mathcal{F} 1978$; 2: 1596-8.

${ }^{6}$ Fox KM, Selwyn AP, Shillingford JP. A method for praecordial mapping of the exercise electrocardiogram. Br Heart f 1978; 40: 1339-43.

'Lanooy C, Bonjer FH. A hyperbolic ergometer for cycling and cranking. F Appl Physiol 1956; 9: 499-500. ${ }^{8}$ Scandinavian Committee on ECG Classification. The 'Minnesota Code' for ECG classification. Adaption to CR leads and modification of the code for ECGs recorded during and after exercise. Acta Med Scand [Suppl] 1967; 481: 1-26.

${ }^{9}$ Reid DS, Pellides LJ, Shillingford JP. Surface mapping of the RS-T segment in acute myocardial infarction. Br Heart f 1971; 33: 370-4.

${ }^{10}$ Whitsitt LS, Lucchesi BR. Effects of propranolol and its stereoisomers upon coronary vascular resistance. Circ Res 1967; 31: 305-17.

${ }^{11}$ Gianelly RE, Goldman RH, Triester B, Harrison DC. Propranolol in patients with angina pectoris. Ann Intern Med 1967; 67: 1216-25.

${ }^{12}$ Prinzmetal M, Toyoshima H, Ekmekci A, Mizuno Y, Nagaya T. Myocardial ischemia. Nature of ischemic electrocardiographic patterns in mammalian ventricles as determined by intracellular electrocardiographic and metabolic changes. Am $\mathcal{F}$ Cardiol 1961 ; 8: 493-503.

${ }^{13}$ Holland RP, Brooks H. TQ-ST segment mapping: critical review and analysis of current concepts. $A m \mathcal{F}$ Cardiol 1977; 40: 110-29.

Requests for reprints to Dr Kim Fox, Division of Cardiovascular Disease, Royal Postgraduate Medical School, Hammersmith Hospital, London W12 0HS. 